\title{
Los Iturralde, plateros en Pamplona (1761-1868)
}

\section{The Iturralde Family, Silversmiths in Pamplona} (1761-1868)

\author{
María Teresa CRUZ YÁBAR \\ Universidad Complutense de Madrid
}

Recibido: 15-IV-2015 / Aceptado: 15-V-2015

ResUMEN: Se recopilan noticias biográficas referentes a los plateros de la familia Iturralde, se aportan nuevos documentos de contratos de obras y se dan a conocer piezas inéditas. Se ha procurado aclarar cuáles fueron las marcas utilizadas por los distintos artífices de este apellido, presentando el dibujo correcto de las mismas y atribuyendo de esta manera las numerosas piezas correspondientes a cada uno de ellos.

Palabras clave: Iturralde, Plata, Siglo XVIII, Siglo XIX, Pamplona, Navarra, San Miguel in Excelsis en Aralar, Mendavia, Mues, Barbarin.

ABSTRACT: This essay contains biographic news about silversmiths who belong to the Iturralde family. It also reveals new documents related to assignments which were ordered them by contract and it is disclosed unpublished pieces. We have tried to clarify which marks were used by the makers of this family, presenting the precise design and attributing each piece of work to one of them.

Keys words: Iturralde, Silver, $18^{\text {th }}$ century, $19^{\text {th }}$ century, Pamplona, Navarra San Miguel in Excelsis in Aralar, Mendavia, Mues, Barbarin.

Suelen crear problemas las obras de platería de una familia cuando no se conocen los datos de nacimiento y muerte de todos ellos, lo que se acrecienta cuando sus marcas -a veces por motivos editoriales- son reproducidas sin precisión ${ }^{1}$. Así sucede con los Iturralde. En este

\footnotetext{
${ }^{1}$ Este artículo es fruto de las investigaciones realizadas en el marco del Proyecto de Investigación "Estudio de la Historia de la Escultura en Madrid entre 1744-1808 sobre una base de datos documentales e imágenes di-
}

trabajo procuramos aclarar ciertas cuestiones al respecto, dar cuenta de algunos contratos de obra y presentar varias piezas inéditas, incluyendo una de función doméstica.

gitalizadas", HAR2010-19400 subvencionado por el MICINN y gestionado por la Universidad Complutense de Madrid (2011-2014). Quiero expresar aquí mi agradecimiento a todo el personal del Archivo Real y General de Navarra y muy especialmente a su jefe de sección don Félix Segura Urra, que tan pronta y amablemente me atendió y ayudó en todo momento. 


\section{FRANCISCO ITURRALDE (1761-1817)}

Francisco Iturralde nació en Arróniz en $1761^{2}$. Comenzó su aprendizaje el 7 de noviembre de 1776 con Juan Francisco Montalbo (Pamplona, 1715-1779) escriturado con una duración de siete años ${ }^{3}$. El contrato preveía que Francisco siguiera trabajando luego como oficial de su maestro, pagándole éste lo acostumbrado 4 . Montalbo fue no sólo un maestro importante, sino también ensayador de la casa de la Moneda, contraste del Reino y marcador de la ciudad. Cuando comenzó Iturralde su aprendizaje, los dos hijos plateros de su maestro, Ignacio y Manuel, que eran mayores que él, ya se habían situado profesionalmente y por tanto pudo recibir una enseñanza personal, pero Montalbo murió no mucho después de que se iniciara el aprendizaje, que no sabemos con quien lo concluiría; pudo ser con Manuel Montalbo pero no con su hermano Ignacio quien, al morir su padre, estaba en paradero desconocido $^{5}$.

Algunas de las siguientes y más tempranas noticias sobre Francisco Iturralde son, sin embargo, curiosas y han dado lugar a varias de nuestras reflexiones y a indagar sobre la veracidad de las mismas o a buscar posibles circunstancias que las expliquen de

\footnotetext{
${ }^{2}$ Archivo parroquial de Arróniz (en adelante APA). Libro III de Bautizados (1740-1795), fol. 82v.; citado por R. FERNÁNDEZ GRACIA, "La estampa devocional en Navarra", en Signos de Identidad histórica para Navarra, Pamplona, 1996, tomo II, p. 194 y nota 67, repetido en ÍDEM, "Plateros-grabadores en Pamplona durante los siglos del Barroco", en J. RIVAS CARMONA (coord.), Estudios de Platería. San Eloy 2004, Murcia, 2004, p. 177 y nota 33. Indica que se llamó Juan Francisco Crisóstomo Iturralde y Cerdán. Aunque no menciona el día del bautizo, hubo de ser cerca del 14 de diciembre en que se celebra la fiesta de san Juan Crisóstomo.

${ }^{3}$ Archivo General de Navarra (en adelante AGN), Protocolos, escribano Nicolás Algarra, 7-11-1776, protocolo no 1198; citado por M. de ORBE SIVATTE, Platería en el taller de Pamplona en los siglos del barroco, Pamplona, 2008, p. 56, nota 66 y documento no 92 y p. 294, nota 203.

${ }^{4}$ M. de ORBE SIVATTE, Op.cit., p. 60.

${ }^{5}$ Sobre los Montalbo cfr. Ibídem, pp. 294-296 y ad indicem.
}

manera coherente. La primera a la que nos referimos es la que comentamos a continuación: En Ollo se conserva una custodia de la que se ha indicado que lleva marcas de Pamplona e Iturralde, además de la cronológica 86 que correspondería a $1786^{6}$, pero no nos consta que en Pamplona se emplearan marcas de este tipo hasta 1792, y la ordenanza al respecto es de $1788^{7}$. Resulta muy extraño que Iturralde recibiera encargos y marcara piezas sin estar aprobado y pensamos que su lectura correcta es 98 leída al revés de cómo se publicó, pues, como indicaremos, el pago de la pieza figura en 1801, lo que parece excesivo retraso, y además hay otras dos piezas suyas de 1796 y 1798 respectivamente.

También es rara la noticia de que el 17 de septiembre de 1788 figure -si bien el último- entre los diecisiete plateros de Pamplona (tres más que se nombran se suponía que estaban ausentes), a quienes se convocó para comunicarles el auto en el que el Real Consejo confirmaba las adiciones a las ordenanzas por las que se regían los plateros ${ }^{8}$. Todos, a excepción de Iturralde, eran artífices aprobados (el nombre transcrito como Miguel de Irízcur ha de ser en realidad Miguel de Irizíbar), aunque ignoramos la fecha en que se examinó Pedro Antonio Sasa. Como no cabe confusión ni errata, sólo se nos ocurre pensar que Iturralde acudió en representación de algún maestro aprobado a pesar de que no se haga constar, pues no parece normal que le convocaran sin estar examinado (no lo estuvo hasta 1792 como luego se indica). También plantea alguna dificultad el relicario de San Román que se conserva en Barbarin, que se ha datado en $1789^{9}$; sospechamos que se trate de una errata, pues todavía no estaba aprobado.

${ }^{6}$ M. C. GARCÍA GAINZA (dir.), Catálogo Monumental de Navarra, Pamplona, 1996, Vol. V**, p. 484.

7 ÍDEM, Antiguos dibujos de los plateros de Pamplona, Pamplona, 1991, p. 50.

${ }^{8}$ Ibídem, pp. 207-208.

${ }^{9}$ ÍDEM (dir.), Catálogo Monumental..., 1982, Vol. II*, p. 351. Probablemente haya de leerse 1799. 
Antes de su aprobación como platero, Iturralde trabajó como grabador. En 1790 retocó la lámina de la escultura titular de la ermita de la Trinidad de Erga, que había abierto Carlos Casanova antes de $1740^{10}$. En 1791 está datada una estampa de Santa Teresa con indulgencias del obispo Aguado y Rojas y en 1793 una carta de confraternización franciscana con imágenes de la Inmaculada y de santos de la orden; además existe otra sin fecha de las Santas Ángela y Jacinta de la Venerable Orden Tercera ${ }^{11}$.

Por fin llegamos a poder mencionar su examen. Dibujó a tinta y lápiz un azafate al que le acompaña el siguiente texto: "Este es el dibujo que elijió por pieza de su examen Francisco Iturralde vecino de esta ciudad y se aprobó por la Hermandad de Artífices plateros en 15 de diciembre de $1792^{\prime \prime 2}$. García Gainza coloca una interrogación junto al año (que ha quedado cortado en la fotografía que incluye) por lo que podría tratarse de alguno anterior, lo que resolvería los problemas antes planteados, pero hay que tener en cuenta que el libro está encuadernado con estricto orden y no se trata de hojas aisladas ${ }^{13}$.

Según observa la autora citada, se trata de una bandeja aovada de gusto neo-

${ }^{10}$ R. FERNÁNDEZ GRACIA, “La estampa devocional...", p. 194 y 190 con nota 47 y "Plateros-grabadores en Pamplona...", p. 172. Según este autor la lámina fue retocada en 1766 añadiéndole esta fecha y las letras de la indulgencia; se modificó después -documentándose los pagos- en 1777, en 1790 por Iturralde que dejó liso el fuste de las columnas del retablo que enmarcaba la imagen (Archivo parroquial de Aguinaga, Libro de cuentas de fábrica de la Ermita de la Trinidad de Erga (1754-1882), fol. 89v.), y en 1793. La estatua gótica se conserva actualmente en la iglesia parroquial de Aguinaga.

${ }^{11}$ R. FERNÁNDEZ GRACIA, “La estampa devocional...", p. 194 y "Plateros-grabadores en Pamplona...", p. 177, pero lamentablemente no reproduce ninguna de ellas ni da referencia de la localización de algún ejemplar.

${ }^{12}$ M. C. GARCÍA GAINZA, Antiguos dibujos..., pp. 135-136 e ilustración no ${ }^{-101}$. R. FERNÁNDEZ GRACIA, "La estampa devocional...", p. 194 afirma, aunque sin citar el origen de la noticia, que el examen fue en 1791.

${ }^{13} \mathrm{El}$ examen previo se fecha en 1791 y el posterior en 1793. clásico y no de contornos con adorno rococó como en otras de exámenes precedentes. Es la primera pieza de examen de este carácter en Pamplona y todavía habrá que esperar a otras dos de 1797 y 1802 para volver a ver el nuevo estilo, pues las demás se siguieron haciendo a la antigua usanza. En la medalla central se representa a una mujer bailando que toca la pandereta entre dos hombres con castañuelas y laúd o mandolina, que llevan larga barba y sombreros en punta y con plumas; los adornos repiten motivos de ondas, pabellones y cadenetas, cintas y perlas.

Los siguientes datos que tenemos sobre el platero nos llevan a 1796. Cerca de 1795 murió Pablo Calleja, que era examinador de la plata nombrado por el ayuntamiento de Pamplona, y en ese año falleció también Martín José Larumbe que estaba designado, también por el ayuntamiento, como tenedor de la arquilla en que se guardaban los instrumentos de marcar. El 27 de agosto de 1796, siendo Manuel Montalbo marcador $\mathrm{y}$ tenedor del arca y custodio de una llave, el ayuntamiento nombró a Pedro Antonio Sasa y a Francisco Iturralde como acompañantes, dándoles sendas llaves del arca. Aceptaron el nombramiento pero poco tiempo después presentaron un memorial exponiendo que les era imposible continuar con los encargos porque no se les asignó salario y "respecto de que las utilidades que rinden son sumamente limitadas, atendida la ocupación personal que acarrean y el tiempo que pierden en desempeñarlas", concluían suplicando que se les asignase un salario anual. El ayuntamiento acordó el 3 de noviembre del citado año otorgarles un salario de 25 ducados anuales a cada uno de los dos (550 reales de plata fuerte a partes iguales entre ellos) y que les empezara a contar desde el 1 de septiembre ${ }^{14}$.

${ }^{14}$ M. y A. de ORBE SIVATTE, "Algunos aspectos sobre el funcionamiento de los plateros de la ciudad de Pamplona", Príncipe de Viana, no 192, 1991, p. 145 y Platería en el taller..., pp. 81-82 y documentos $\mathrm{n}^{\mathrm{o}} 98$ y 99. J. F. GARRALDA ARIZCUN, "La burocracia del Ayuntamiento de Pamplona del siglo XVIII", Príncipe de Viana, no 191, 1990, pp. 891-893, recogía ya la noticia 
La primera noticia que tenemos de la actividad del platero tras su aprobación procede del santuario de San Miguel in Excelsis en cuyas cuentas de 1796 se anota la siguiente partida: "Dados a Francisco Iturralde, platero, que vino al santuario con su criado a componer el relicario de la imagen de San Miguel, 87 reales, 4 maravedís"15.

Hemos encontrado sendos contratos de las primeras piezas realizadas también tras el examen: para la iglesia parroquial de Mendavia en ese mismo año 1796 y para el santuario de San Miguel in Excelsis al año siguiente. No se ha conservado nada de lo documentado pero las escrituras proporcionan muchas noticias de interés.

El 6 de diciembre de 1796 en la sacristía de la iglesia de Mendavia, se reunieron el Cabildo eclesiástico y la comunidad secular de la villa, como administradores de la fábrica parroquial, con Francisco Iturralde, maestro platero y vecino de la ciudad de Pamplona ${ }^{16}$. Expusieron que por manda-

(p. 893) de esta solicitud de los ayudantes de Montalbo -que desde ese mismo 27 de agosto de 1796 concentraba en su persona los cargos de contraste y marcador del oro y de la plata, y refinador de pesos y medidas- en la que justificaban su petición en que "ni ellos ni ninguno de los demás plateros habían pensado en solicitar los referidos empleos, sin embargo de haber algunos años que estaban vacantes" (Archivo Municipal de Pamplona, Consultas, Libro 60, fol. 23r.; 9-11-1796). El mismo autor dice que ostentaron el cargo hasta 1803, año en que también Montalbo dejó de ocupar todos los suyos.

${ }^{15}$ Libro nuevo de cuentas del santuario de San Miguel de Excelsis (1790-1844), manuscrito de Mariano Arigita, con prólogo fechado en 1914. Este manuscrito, cuyo paradero actual se ignora, fue publicado por J. GOÑI GAZTAMBIDE, "San Miguel de Excelsis y la chantría de Pamplona, de M. Arigita", Príncipe de Viana, no ${ }^{-124-}$ 125, 1971, pp. 145-175 (noticia en p. 160) y este estudio se ha recogido de nuevo en Príncipe de Viana, no 251, 2010; la noticia en p. 1142.

${ }_{16}$ AGN, Protocolos, escribano José Carlos Tabar, caja 21.262/1, no 21; el documento se protocolizó ante el escribano Manuel de Almazán que rubrica la copia y su traslado al protocolo de Tabar. Los presentes fueron don Ramón de Sádava, vicario, el licenciado don Joaquín de Irigoyen, don Juan Agustín Sagredo, don Félix Ximénez, don Joaquín de Belunza y don Diego Ordóñez, presbíteros y beneficiados que constituían el cabil- to del señor provisor y vicario general del Obispado y auto de dichas comunidades de 7 de septiembre de 1794, entregaron al Reino, junto en Cortes generales, varias alhajas de la iglesia en calidad de préstamo para "atender a la guerra que S. M. tenía por entonces con Francia". Las piezas cedidas fueron una lámpara, unos cetros, una cruz, seis candeleros, cuatro platillos y otras que no se mencionan. El Reino había donado después, seguramente en tiempo reciente, alguna cantidad de dinero como contrapartida y como la iglesia tenía necesidad de reponer muchas de las dichas alhajas "para su mayor ornato y decencia", se concertaron con Iturralde para que las hiciera.

La relación de piezas que se señaló, con el peso indicado en onzas (28'75 gramos) de cada una fue la siguiente: Lámpara (400), cruz y seis candeleros de mesa de altar (370), cruz de procesiones (120), calderilla o acetre e hisopo (80), dos cetros (120), cuatro pares de vinajeras con sus platillos (48) y otras dos y platillos grandes (24) y sacra de palabras de la Consagración (40), en total 1.202 onzas.

Asimismo se establecían las siguientes condiciones: $1^{\underline{a}}$ ) Todas las piezas y especialmente la lámpara y la sacra debía fabricarlas el platero "con el mayor primor, a la moda moderna y según arte e idea que ha presentado a ambas comunidades"; $2^{\text {a }}$ ) a todas las alhajas debía de poner las piezas de bronce de sobrepuestos dorados según correspondiese; $3^{\underline{a}}$ ) se le pagaría a diez reales y medio de plata fuerte ${ }^{17}$ cada onza de material y a cuatro y medio la hechura de cada una, y lo mismo por su labor en cada onza de las de bronce sobredoradas; también le pagarían el valor del bronce y oro que pusiera; $4^{\underline{a}}$ ) se le

do eclesiástico; y por otra parte los miembros del patronato secular, Juan Ramón Marquínez, Manuel Lodosa y Jorge Sainz, teniente de alcalde y regidores. Los testigos fueron Antonio Maestre menor y Leonardo Ramírez de Orisuain, vecinos de la villa.

${ }^{17} \mathrm{El}$ real de plata fuerte a finales del siglo XVIII en Navarra equivalía a 2 reales de vellón (M. POY Y COMES, Tratado de Cambios patricio, provincial, nacional y estrangero. Parte Primera (Adiciones y notas de Salvador Ros y Renart), Barcelona, 1828, p. 73. 
adelantaría el importe de la plata de la pieza por la que fuera a empezar y al entregarla se echaría la cuenta y se le daría inmediatamente lo que se le debiera y así se haría sucesivamente con las demás; $5^{a}$ ) el platero habría de dar fianzas en la ciudad de Pamplona y los firmantes de la otra parte se obligaban a cumplir lo que les tocaba renunciando a la restitutio in integrum y sometiéndose a la jurisdicción según las fórmulas usuales.

Antes de firmar la escritura, añadieron a las piezas citadas las sacras de lavabo y último Evangelio, con peso de 20 onzas cada una. Se le autorizaba a aumentar el peso total de 1.242 onzas hasta 1.300 , pero si sobrepasaba este último, no se le pagarían las hechuras y sí el valor de la plata.

El 23 de enero del año siguiente, 1797, se firmó una nueva escritura, ahora en Pamplona, de las fianzas exigidas ${ }^{18}$. Se repite la relación de piezas y su peso, la cantidad a pagar por los materiales y la hechura y la manera de hacerlo, pero se añaden algunas noticias de interés: Iturralde había presentado "siete planos o diseños" al patronato eclesiástico y secular de la parroquial de Mendavia. Además, le encargaron que hiciera la cruz de altar y los seis candeleros, los dos cetros y las tres sacras, debiéndolo traer todo acabado dos días antes de la próxima festividad de San Juan, advocación del templo. Hicieron entrega en el acto al platero de 600 pesos duros (6.000 reales fuertes) que era prácticamente el importe de las 570 onzas de plata precisas para las piezas indicadas, de lo que otorgó carta de pago. En cuanto a los fiadores, presentó Iturralde a su mujer Josefa Gambarte -posiblemente hija del platero José Gambarte, nacido en Corella y aprobado en Pamplona en 1765- y a Melchor Arístegui, vecino de Pamplona, de quien no se indica profesión; ambos firman al final de la escritura. Todavía al final del documento aparece otra noticia: seis diseños queda-

18 AGN, Protocolos, escribano José Carlos Tabar, caja 21.262/1 no 21. (Apéndice documental, Doc. 1). Los testigos fueron Manuel Pinillos y Juan José Uribarrena, vecinos y residentes en la ciudad. ron firmados por Iturralde y el escribano y el séptimo era "conforme al de la lámpara que está haciendo el mismo Iturralde para la capilla de Nuestra Señora del Camino". De esta manera conocemos la realización de otra pieza por parte del artífice aunque la lámpara de la capilla de la Virgen del Camino en la iglesia parroquial de San Saturnino de Pamplona tampoco se ha conservado.

Fernández Gracia indicó que en este año 1797 fue nombrado "accidentalmente" platero de San Saturnino -lo que explica el encargo de la lámpara para este templo que hemos documentado-, oficio que desempeñó hasta 1804, en que pasó a ser sobrestante de fundiciones de la real fábrica de Orbaiceta $^{19}$.

La fabricación de lámparas se acrecentó en el reino de Navarra durante los últimos años del siglo XVIII, tal y como se desprende de la documentación conservada. El diseño de Iturralde debió de ser de gran calidad, y su atractiva modernidad, que denominamos neoclásica, resultó convincente pues, además de los dos ejemplares citados, hemos hallado la escritura de realización de otra lámpara para la capilla de San Miguel in Excelsis, el santuario de San Miguel de Aralar. El contrato se firmó el 25 de abril de 1797, fecha en que se reunieron en Pamplona don Juan Miguel de Ochotorena, presbítero, ministro de dicha capilla, y Francisco Iturralde, que se obligó a construir una lámpara para la capilla citada antes del día de San Miguel, su titular ${ }^{20}$. El diseño debía de ser realizado con 200 onzas de plata (la mitad de lo que había de pesar la lámpara de Mendavia). El precio total no debía exceder de 3.450 reales

\footnotetext{
${ }^{19}$ Archivo parroquial de San Saturnino de Pamplona (en adelante APSSP), Libro de Autos y Resoluciones de la Obrería (1787-1813), fols. 153r. y 220v., citado en R. FERNÁNDEZ GRACIA, “La estampa devocional...", p. 194 y nota 69 y "Plateros-grabadores en Pamplona...", p. 177 y nota 35.

${ }^{20}$ AGN, Protocolos, escribano Faustino Ibáñez, 254-1797, caja 21.453, no 20 . Firman como testigos Francisco Javier Lorenzo y José Visayres. Ochotorena ejerció el empleo de ministro desde mayo de 1764 hasta 1797 en que murió; era natural de Baráibar.
} 
fuertes, más el oro que entrase en el dorado de los bronces, que se pagaría a cinco pesos por escudo. La onza de plata seguía en el precio fijo de diez reales y medio, pero en este ejemplar la hechura sólo se pagaría a cuatro reales fuertes cada onza; el bronce se fija en tres pesos fuertes por onza.

La realización de esta lámpara hubo de estar motivada porque don Fernando de Beregaña había regalado al santuario una lámpara de plata de 755 onzas y 2 ochavas de peso, que el Reino había reducido a dinero por las urgencias de la guerra, pagando 7.552 reales y 18 maravedís ${ }^{21}$. La nueva lámpara iba a sustituir a la antigua aunque se preveía más pequeña.

Las piezas conservadas son numerosas y han sido recogidas en el Catálogo Monumental de Navarra salvo un par de candeleros y las que ahora damos a conocer por primera vez: un portavinagreras de colección particular subastado recientemente en Madrid $^{22}$, un copón de la iglesia parroquial de Legaria y una custodia de la de Mués. Las ordenaremos cronológicamente advirtiendo, como ya se insinuó, que todas ellas responden a las características del llamado estilo neoclásico.

El recado de vinagrera y aceitera está marcado en 1796 y es una de las dos piezas de platería doméstica de las que tenemos constancia que existen de este artífice; es sabido que son muy escasas las obras marcadas en Pamplona no litúrgicas que han sido publicadas. Los pocillos apoyan sobre cuatro soportes de doble vástago y avolutados con guirnaldas colgantes; la mitad de su boca está rodeada por una rama de

${ }^{21}$ Libro nuevo de cuentas del santuario de San Miguel de Excelsis (1790-1844), manuscrito de Mariano Arigita... en: J. GOÑI GAZTAMBIDE, “San Miguel...", p. 160 (ver nota 14 de este artículo). La aprobación de cuentas del santuario por el chantre don Antonio Mendinueta, se hizo en Pamplona al día siguiente de la firma del contrato con Iturralde, por lo que ya quedó aprobada la escritura.

${ }^{22}$ Abalarte, Madrid 8-10-2014, lote 458; salida en 350 $y$ remate en 550 euros sin comisiones. laurel que se anuda al pie del vástago entre los anillos para dejar los tapadores de las botellas de cristal que se han conservado completas. El vástago se sitúa, de manera inusual, perpendicularmente a los pocillos; abalaustrado, con estrías y hojas de acanto, remata en una anilla con laurel y lazo como en su base. Los pocillos se unen abajo mediante una flor de ocho pétalos ${ }^{23}$ (Figs. 1-4).

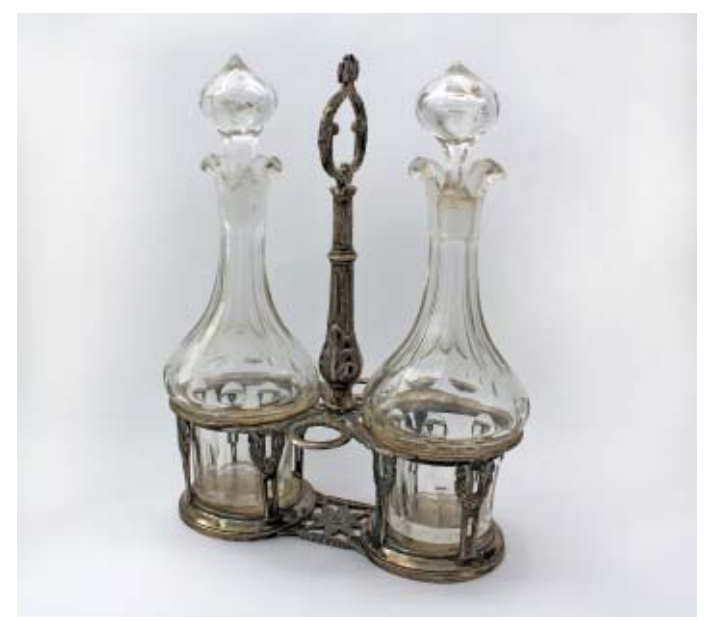

- Fig. 1. Portavinagreras. Francisco Iturralde, 1796. Madrid, Colección particular. Foto de la autora.

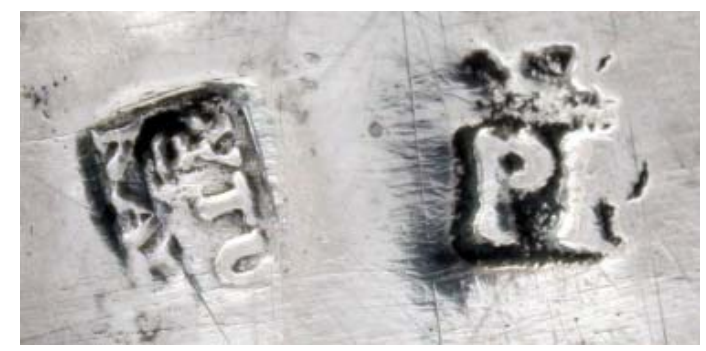

- Fig. 2. Portavinagreras. Francisco Iturralde, 1796. Madrid, Colección particular. Marcas de artífice y localidad. Foto de la autora.

${ }^{23}$ Plata moldeada, fundida y troquelada. $23 \mathrm{~cm}$ de altura, $18 \times 9 \mathrm{~cm}$ la base; 6,7 y 7,5 cm de altura y de diámetro de los pocillos. 400 gr. Marcas en el centro del anverso de los pocillos: PP con corona de tres picos e YTUR/RALDE en parte frustra en uno y 96 y la de artífice, también incompleta, en el otro; burilada en el reverso de uno de los pocillos. Grabadas en la superficie del anillo de uno: $\mathrm{JL}^{\mathrm{A}}$. 


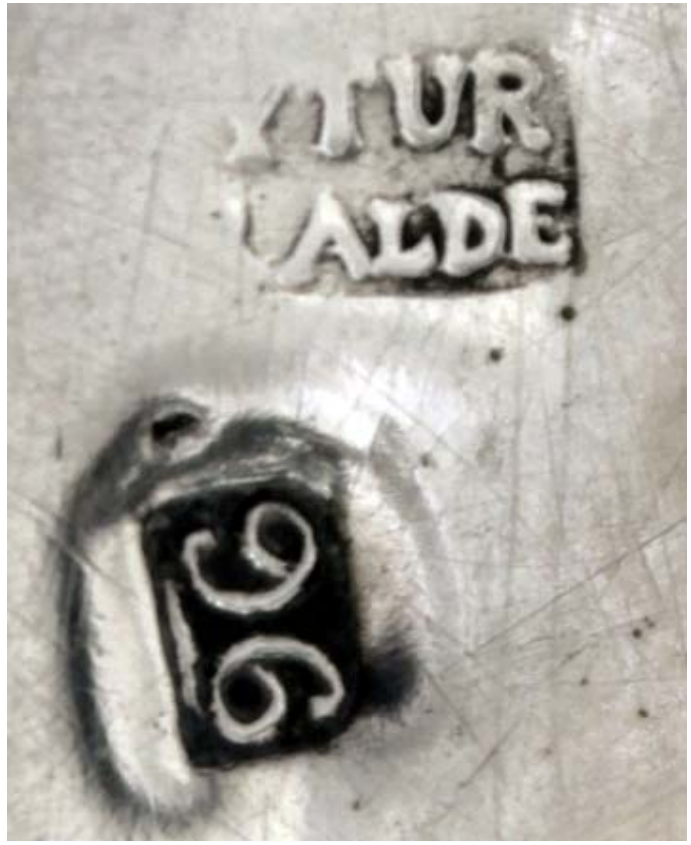

- Fig. 3. Portavinagreras. Francisco Iturralde, 1796. Madrid, Colección particular. Marcas de artífice y cronológica. Foto de la autora.

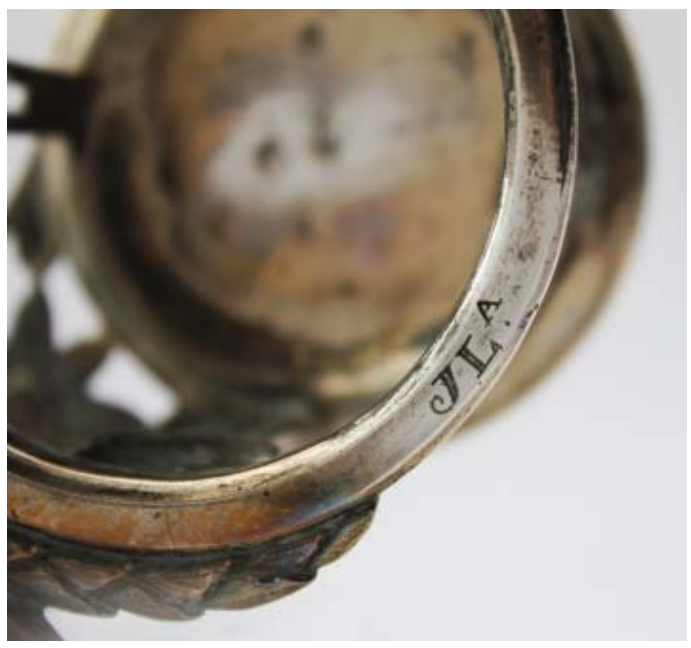

- Fig. 4. Portavinagreras. Francisco Iturralde, 1796. Madrid, Colección particular. Iniciales del propietario. Foto de la autora.

En el año 1797 está marcada la pareja de portapaces con Ecce Homo y Virgen con el Niño de Obanos ${ }^{24}$. Marca de 1798 lleva el relicario, de tipo sol, de Santo Tomás, titu-

${ }^{24}$ M. C. GARCÍA GAINZA (dir.), Catálogo Monumental..., Vol. V**, p. 345. lar del templo, de Ollo 25 ; también, como se señaló, la custodia es probable que esté realizada cerca de o en ese año, pues se anota el pago en las cuentas de 1801, indicando que se le entregaron 1.457 reales y 32 maravedís y además se le dio la custodia vieja. La platería doméstica navarra no está estudiada, por eso cobra más valor la publicación de una pareja de candeleros de columna (colección particular) de $1799^{26}$. Consta que en 1801 Iturralde formaba parte de la hermandad de San Eloy de plateros de Pamplona, lo que seguramente sucedió desde su aprobación hasta su muerte, pero figura entre los veinte cofrades que ese año ganaron el pleito contra un platero que tenía tienda abierta en Tafalla sin estar aprobado como maestro ${ }^{27}$. En 1802 está marcado un cáliz de Allo ${ }^{28}$.

La actividad de Iturralde como platero no se documenta después de ese año ${ }^{29}$ -recordemos que desde 1804 trabajaba en Orbaiceta- hasta 1810 (o mejor, tras 1812) lo que se explica también por los acontecimientos bélicos. En 1810 se ha datado un cáliz de Murugarren $^{30}$; es un año en que apenas se conoce alguna pieza de plata en toda España por motivo de la invasión napoleónica, pero en el que se marcó en Pamplona con seguridad.

En las cuentas de 1814 del santuario de San Miguel in Excelsis figura el pago de 38 reales y 28 maravedís a Iturralde "por composición del relicario de la santa imagen

${ }^{25}$ Ibídem, p. 485.

${ }^{26}$ A. FERNÁNDEZ, R. MUNOA y J. RABASCO, Enciclopedia de la plata española y virreinal americana, Madrid, 1985 (2ª ed. de los autores), no 961 (con ilustración de las piezas y las marcas).

${ }^{27}$ M. de ORBE SIVATTE, Platería en el taller..., p. 100, nota 111 .

${ }^{28}$ M. C. GARCÍA GAINZA (dir.), Catálogo Monumental..., Vol. II*, p. 116.

${ }^{29}$ Ver nota 13 de este artículo, especialmente J. F. GARRALDA ARIZCUN, "La burocracia del Ayuntamiento...", pp. 891-893.

${ }^{30}$ M. C. GARCÍA GAINZA (dir.), Catálogo Monumental..., 1983, Vol. II**, p. 728. 
del santo Arcángel"31; seguramente, el motivo fue el deterioro que causaron los franceses durante las varias ocasiones en que estuvieron en el santuario. Aunque no figura el nombre del platero, es muy probable que también fuera Iturralde quien reparara el relicario tras el robo el 11 de mayo de 1797 y la composición que se hizo en $1806^{32}$.

En 1812 los franceses robaron la custodia de Barbarin y en 1815 se dio licencia a la iglesia para hacer, según el presupuesto del platero, la que se conserva, sin marca cronológica, de bronce sobredorado ${ }^{33}$. Está adornada con cuatro medallas sobrepuestas de plata en el pie que tienen instrumentos de la Pasión (cruz, corona de espinas, esponja y lanza; columna, gallo, INRI y escalera) y alegorías eucarísticas (cordero apocalíptico; pelícano con las crías) ${ }^{34}$. Otra custodia de Ganuza está fechada en $1815^{35}$ y al año siguiente hizo otra custodia, similar a las precedentes, y un cáliz para Andosilla ${ }^{36}$.

En las cuentas de 1816 de la iglesia parroquial de Legaria se anotan 427 reales fuertes que se le pagaron al platero por un copón, sin adorno, (Fig. 5) que tiene las marcas de aquel año, la de localidad y la de artífice, en el borde vertical del pie ${ }^{37}$ (Fig. 6).

${ }^{31}$ Libro nuevo de cuentas del santuario de San Miguel de Excelsis (1790-1844), manuscrito de Mariano Arigita... en: J. GOÑI GAZTAMBIDE, “San Miguel...", p. 162 y p. 1143 respectivamente (ver nota 14 de este artículo).

${ }^{32}$ Ibídem para las fechas de las restauraciones.

${ }^{33}$ Archivo Diocesano de Pamplona, Fajo de obras, A-17, no 29 en: I. MIGUÉLIZ VALCARLOS, "Pérdida de las alhajas de plata de la Iglesia en Navarra durante la guerra de la Independencia (1808-1814)", Príncipe de Viana, no 256, 2012, p. 757. M. C. GARCÍA GAINZA (dir.), Catálogo Monumental..., Vol. II*, p. 351.

${ }^{34}$ Ibídem, p. 728.

${ }^{35}$ Ibídem, Vol. II**, p. 360

${ }^{36} \mathrm{Ibídem}$, Vol. II*, p. 172.

${ }^{37}$ Archivo parroquial de Legaria, Libro de fábrica IV (1804-1849), cuentas de 27 de junio de 1816. Mide 27,5 cm y $21 \mathrm{~cm}$ de altura con y sin tapa, $10 \mathrm{~cm}$. de diámetro de boca y $13,3 \mathrm{~cm}$ de diámetro de pie. No figura en el Catálogo Monumental de Navarra. Fue estudiado en 1979 por el profesor Cruz Valdovinos, catedrático de Historia

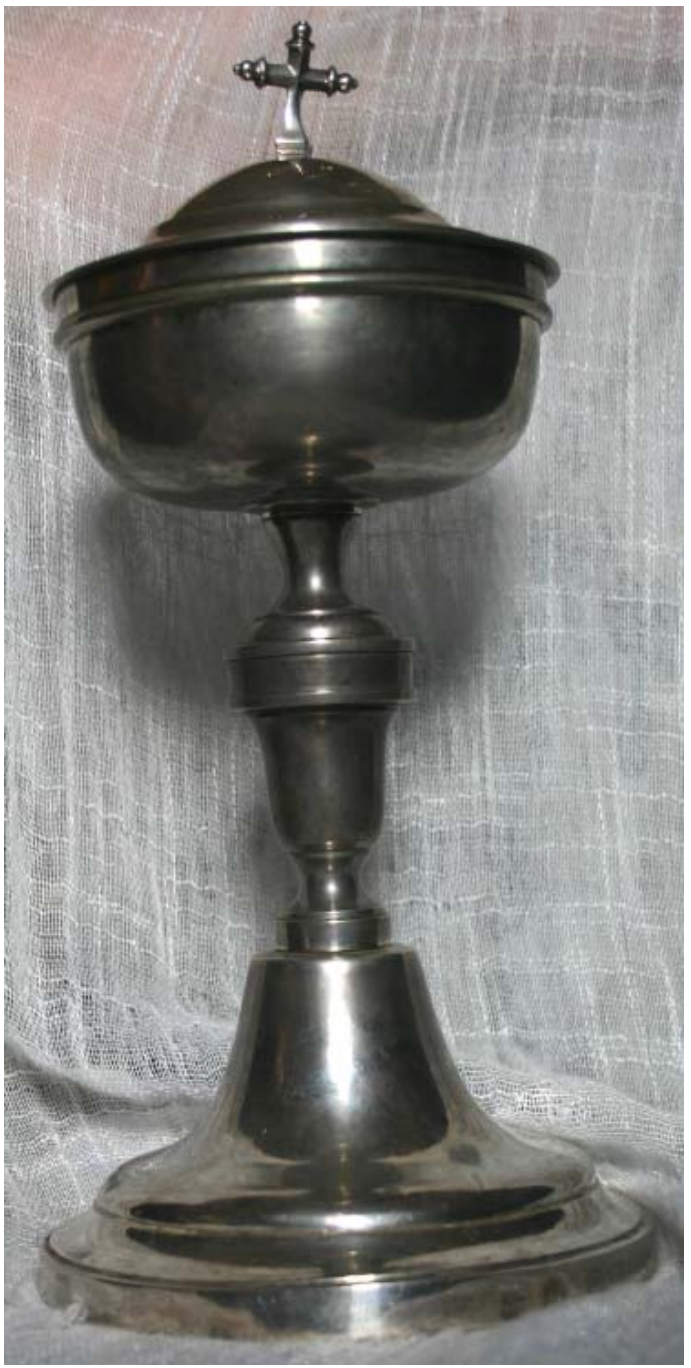

- Fig. 5. Copón. Francisco Iturralde, 1816. Legaria, iglesia parroquial. Foto de la autora.

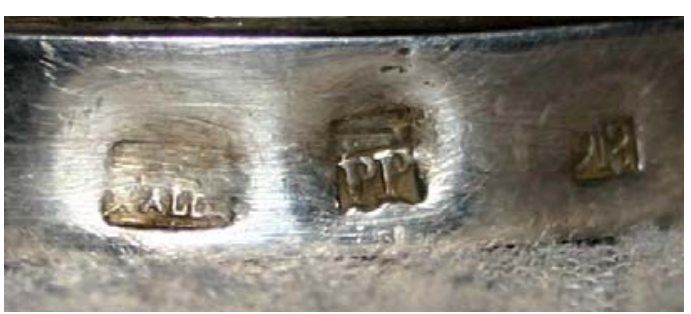

- Fig. 6. Copón. Francisco Iturralde, 1816. Legaria, iglesia parroquial. Marca de artífice, localidad y cronológica. Foto de la autora.

del Arte de la Universidad Complutense de Madrid, a quien debo estas noticias, que han sido comprobadas en un viaje reciente en 2014, donde hemos fotografiado la pieza y su marca. 


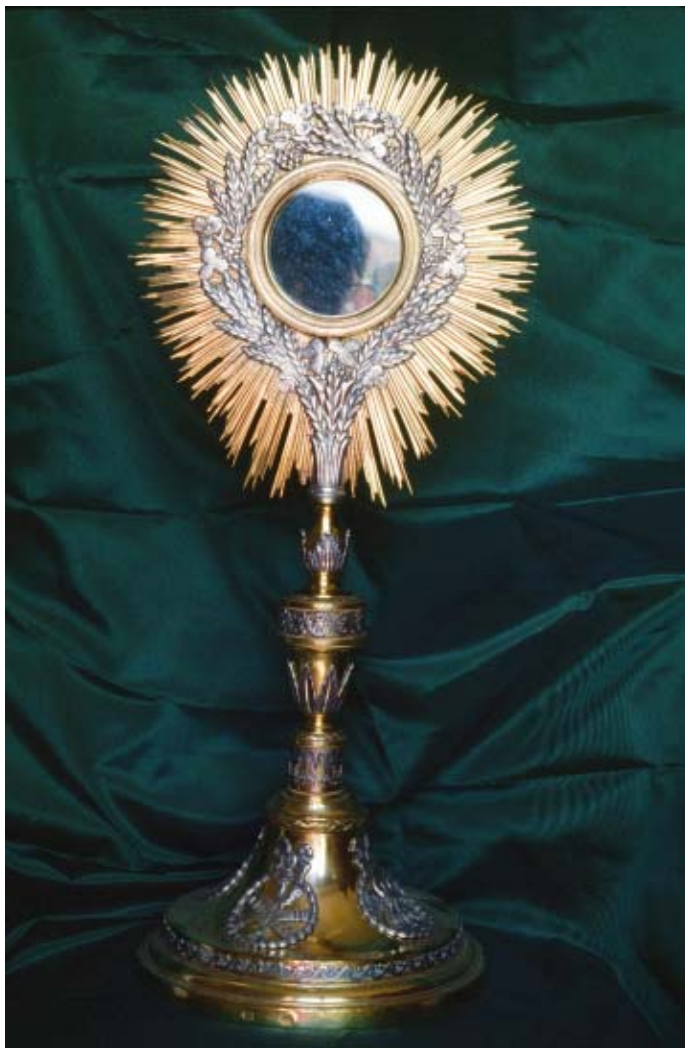

- Fig. 7. Custodia. Francisco Iturralde, ¿1812/1816?. Mues, iglesia parroquial. Foto de la autora.

Un caso peculiar es el de la custodia de Mues (Fig. 7) que lleva sólo la marca de artífice (Fig. 8), como la de las piezas precedentes. En las cuentas tomadas el 9 de febrero de 1841 (correspondientes a los dos años anteriores) se anota la siguiente partida de descargo: "Iten de veinte y un reales de plata fuertes, los mismos se pagaron por el cambio de custodia, que valen más la que traje que la que se $\mathrm{dio}^{\prime \prime 38}$. La custodia es de bronce dorado con sobrepuestos de plata como las anteriores. Lo mismo que otras de Iturralde, tiene espigas y racimos alrededor del viril, además de prolongadas ráfagas de muchos

${ }_{38}$ Archivo parroquial de Mues, Libro de fábrica III (1796-1880), fol. 205r. La custodia vieja era de 1659. La nueva mide $53 \mathrm{~cm}$ de altura, $24 \mathrm{~cm}$ de anchura, $21 \mathrm{~cm}$ de diámetro de pie y $9,5 \mathrm{~cm}$ de diámetro de viril. Tiene la marca de artífice repetida en el borde vertical del pie. No figura en el Catálogo Monumental. Fue estudiada el 27 de agosto de 1979. Agradezco las noticias al doctor Cruz Valdovinos. rayos. En los sobrepuestos del pie se adorna con pelícano con crías, corona de espigas, vergajo, cruz, caña con esponja y lanza, cordero apocalíptico y columna, gallo, dados, INRI y escalera. Resulta coincidente en material, dimensiones, tipo y motivos iconográficos con las de Barbarin, Ganuza y Andosilla y pensamos que con el mismo diseño y moldes se pudieron fabricar algunas custodias que no se llevaron al marcador y que se vendieron luego a iglesias que las necesitaban. Es probable que la custodia de Goñi, que tampoco lleva marca cronológica ${ }^{39}$, sea un ejemplar en las mismas circunstancias. Como luego se explica, esta variante de la marca, que corresponde a Francisco Iturralde, está documentada hasta 1816.

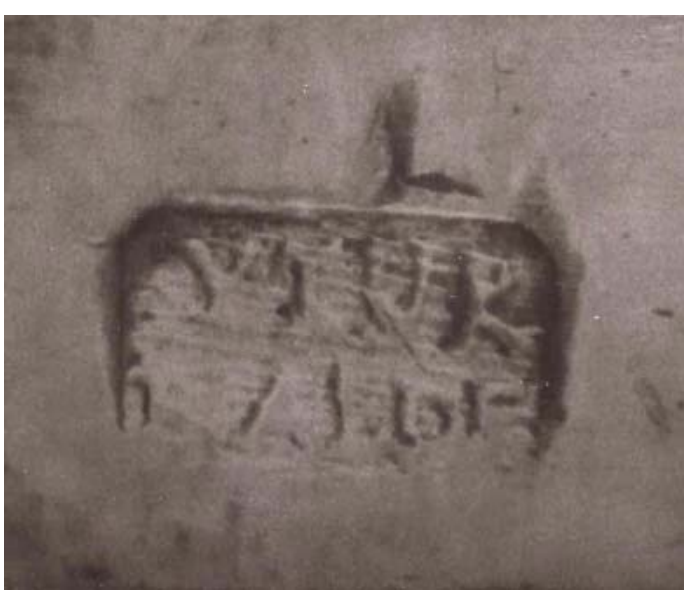

- Fig. 8. Custodia. Francisco Iturralde, ¿1812/1816?. Mues, iglesia parroquial. Marca de artífice. Foto de la autora.

Las obras mencionadas hasta ese año 1816 llevan la misma marca de artífice -además de la de localidad de Pamplona y la cronológica de dos o tres cifras con variación anual, en casi todos los ejemplares-, que consiste en el apellido con " $Y$ " y partido en dos líneas: "YTUR/RALDE" (Fig. 9). Aunque alguna vez no se ha transcrito la marca con exactitud o no aparece completa, no hay duda de que empleó siempre esa variante durante esta etapa. Esto se confirma porque

${ }^{39}$ M. C. GARCÍA GAINZA (dir.), Catálogo Monumental..., Vol. II**, p. 31. 
su fallecimiento tuvo lugar en Pamplona en $1817^{40}$.

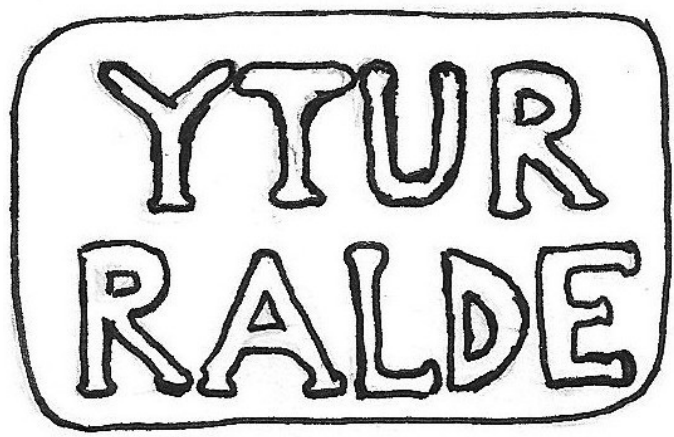

- Fig. 9. Marca de Francisco Iturralde (1761- post. 1816). Dibujo de la autora.

\section{JOSÉ ITURRALDE (1781 - 1842)}

Tras un período de siete años en el que no conocemos ninguna pieza con marca de este apellido, aparecen algunas fechadas, por la marca cronológica, entre 1824 y 1832. De 1824 es una cuchara (colección particular $)^{41}$ que sigue demostrando que en el obrador se realizaron piezas de uso doméstico. En 1832 está datado un juego de altar de Erasun con cáliz, vinajeras y platillo ${ }^{42}$; además de la marca cronológica, lo confirma la inscripción de donación que ostenta el cáliz: "Regalo de don Pedro Ignacio Garbiso, arcediano de Santa Gema a la parroquial de Erasun. Año de 1832" (en mayúsculas y con algunas abreviaturas). También llevan marca de 1832 unas crismeras de arqueta de Eguiarreta, con inscripción en el reverso de la base que indica: "Eguiarreta Valle Araquil" (en mayúsculas y Valle abreviado). Al inventariarlas, se publicó que en ese año se le pagaron 236 reales fuertes al platero José Iturralde por las piezas, noticia procedente

${ }^{40}$ APSSP, Libro VI de Difuntos (1811-1853), fol. 54v., citado en R. FERNÁNDEZ GRACIA, “La estampa devocional...", p. 194 y nota 68 y "Plateros-grabadores en Pamplona...", p. 177 y nota 34.

${ }^{41}$ A. FERNÁNDEZ, R. MUNOA y J. RABASCO, Op.cit., $\mathrm{n}^{\circ} 970$.

${ }^{42}$ M. C. GARCÍA GAINZA (dir.), Catálogo Monumental..., 1994, Vol. V*, p. 620. de los libros de fábrica de la iglesia ${ }^{43}$. Aunque la marca de artífice se ha transcrito como la empleada hasta 1816 -que corresponde, por tanto, a Francisco-, opinamos que es una errata, pues también se ha hecho así con las piezas de Erasun cuando la marca es "Ytur/ ralde" (en cursiva), lo mismo que en la cuchara de 1824; por tanto afirmamos que, de 1824 al menos hasta 1832, se empleó la marca con " $Y$ " y el resto en letras minúsculas cursivas en dos líneas (Fig. 10). Hemos de pensar que si en Eguiarreta se pagó a José Iturralde, éste ha de ser el artífice que hizo las piezas del período indicado.

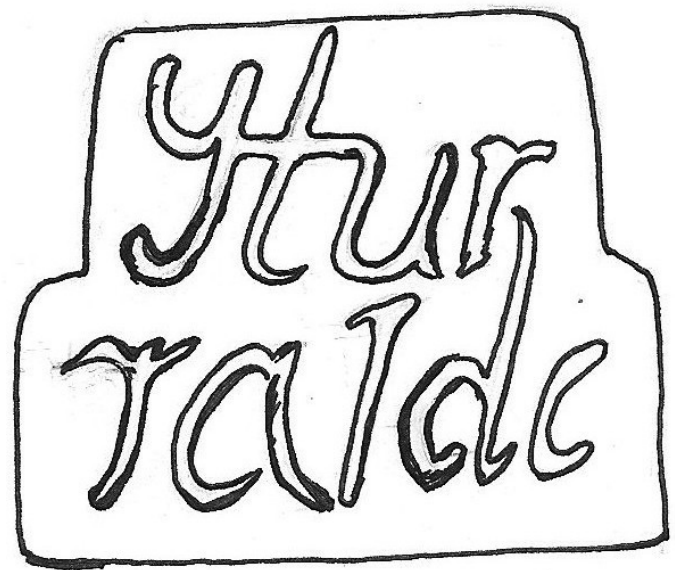

- Fig. 10. Marca de José Iturralde (act. 1803-1832). Dibujo de la autora.

En efecto, en 1803 realizó el dibujo de examen un platero de ese nombre, natural de Arróniz y vecino de Pamplona ${ }^{44}$; la pieza que eligió fue una salva de contornos, si bien los pies son de carácter clásico. García Gainza afirma que sería hermano o familiar de Francisco, y Fernández Gracia señala que eran hermanos ${ }^{45}$. Aparece como vecino de Pamplona al examinarse. Fernández Gracia

\footnotetext{
${ }^{43}$ Ibídem, pp. $158-159$.

${ }^{44}$ ÍDEM, Antiguos dibujos..., p. 140 e ilustración $n^{\underline{0}}$
} 114 .

${ }^{45}$ APA, Libro III de Bautizados (1740-1795), fol. 209r. citado en R. FERNÁNDEZ GRACIA, “La estampa devocional...", p. 194 y nota 70 y "Plateros-grabadores en Pamplona...", p. 177 y nota 36; señala que José Matías nació en 1781. Por el nombre suponemos que en febrero. 
publicó la noticia de que su mujer se llamaba Marciala de Aizpún ${ }^{46}$ y Morales Solchaga ha presentado la relación de oficios que ocupó en la hermandad de San Eloy: mayordomo $(1805 / 1806)$, prior $(1807 / 1808)$, mayordomo (1808/1809), luminero (1827/1828), prior (1829/1830), mayordomo (1830/1831), luminero $(1836 / 1837)$ y prior $(1838 / 1839)^{47}$. Falleció en Pamplona en agosto de $1842^{48}$.

Como mera hipótesis, que la investigación confirmará o rechazará en el futuro, proponemos, que siendo parientes -probablemente hermanos-, Francisco acogería a José en su obrador e incluso pudo ser su maestro $^{49}$. Tras la aprobación, el menor seguiría colaborando con Francisco. La variación en la marca personal se explica por la muerte de este último. Morales ha indicado que Francisco Iturralde aparece en 1828 como receptor del dinero de la función de San Eloy en San Cernin ${ }^{50}$. Opinamos que ha de ser una errata del propio escribano y en realidad se trata de José, pues si hubiera habido un platero en esa fecha con el mismo nombre que el fallecido en 1817 habría tenido que pasar el examen de aprobación como maestro, lo que no sucedió.

José Iturralde actuó en sus comienzos como grabador, igual que Francisco. Se conoce una estampa de la Virgen de Mendía de Arróniz de 1821 y pequeñas planchas -quizá destinadas a estampar escapularios-, de la Inmaculada, los Sagrados Corazones y la Virgen del Carmen; además retocó otras de

${ }^{46}$ R. FERNÁNDEZ GRACIA, "La estampa devocional...", p. 194.

${ }^{47}$ E. MORALES SOLCHAGA, "La Constitución de Cádiz y la disolución de los gremios: el caso de los plateros pamploneses", Príncipe de Viana, n⿳0 256, 2012, pp. 775,776 y 780 .

${ }^{48}$ APSSP, Libro VI de Difuntos (1811-1853), fol. 277v, citado en R. FERNÁNDEZ GRACIA, "La estampa devocional...", p.194 y nota 72 y "Plateros-grabadores en Pamplona...", p. 177 y nota 38. Indica que murió en agosto.

${ }^{49}$ También lo piensa así E. MORALES SOLCHAGA, Op.cit., p. 777.

${ }^{50}$ Ibídem, p. 779. la Virgen de Musquilda y de la del Camino y de San Joaquín ${ }^{51}$.

No acaban con esto las cuestiones que plantean las piezas con marcas personales de Iturralde. De 1833 es un hostiario de Ugar cuya marca se ha transcrito con mayúsculas en una sola línea (Fig. 11) ${ }^{52}$, igual que en la sencilla corona de la Virgen del Rosario de Pina de $\mathrm{Ebro}^{53}$. Así ocurre también con certeza en una cuchara (colección particular) de $1837^{54}$. Lo mismo sucede con un cáliz del convento de agustinas recoletas de Pamplona de $1841^{55}$, que se ha atribuido con dudas a José Iturralde ${ }^{56}$. Para mayor complicación, la salvilla de las vinajeras de Murugarren ha sido datada en 1840 -aunque, según advertimos, el cáliz de la misma iglesia se fecha en 1810- y las marcas personales de ambas piezas se han transcrito (que no reproducido con foto o con dibujo) con mayúsculas y partiendo el apellido de manera no vista antes: "ITU/RRALDE", lo que, sin poderlo comprobar personalmente, consideramos que no es correcto. Parece evidente que José

${ }^{51}$ R. FERNÁNDEZ GRACIA, “La estampa devocional...", p. 194 y "Plateros-grabadores en Pamplona...", p. 178, pero lamentablemente tampoco en esta ocasión reproduce ninguna de ellas ni da referencia de la localización de algún ejemplar. De la Virgen del Camino, abierta en 1721, comenta que José Iturralde suprimió parte de los círculos inferiores en donde se cobijan san Fermín y san Saturnino para añadir una inscripción de indulgencias.

${ }^{52}$ M. C. GARCÍA GAINZA (dir.), Catálogo Monumental..., Vol. II ${ }^{* *}$, p. 740.

${ }^{53}$ A. LACARTA APARICIO, R. CUENCA MORENO y E. PLANA MENDIETA (coords.), "La Virgen del Rosario de Pina de Ebro: un tesoro recuperado", en Investigación y patrimonio en la provincia de Zaragoza Vol. I (en línea), Zaragoza, 2008, pp. 6-7 (con ilustración), consultado el 17 de julio de 2013. URL: http://ifc.dpz.es/ recursos/publicaciones/27/86/7.VirgenPinadeEbro.pdf

${ }^{54}$ A. FERNÁNDEZ, R. MUNOA y J. RABASCO, Op.cit., $\mathrm{n}^{\mathrm{o}} 973$ (se reproduce dibujo de la marca).

${ }^{55}$ M. y A. de ORBE SIVATTE, “Orfebrería del convento de agustinas recoletas de Pamplona", Príncipe de Viana, no 186, 1989, p. 18 (con ilustración).

${ }^{56}$ M. C. GARCÍA GAINZA (dir.), Catálogo Monumental..., 1997, Vol. V***, p. 336. 
Iturralde cambió su punzón en 1833 usando la nueva variante hasta su muerte.

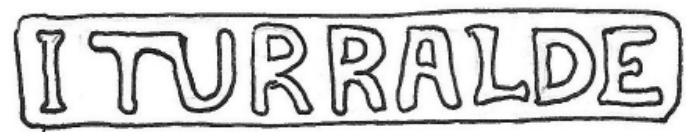

- Fig. 11. Marca de ¿José? Iturralde (utilizada 1833-1841). Dibujo de la autora.

\section{RAMÓN ITURRALDE (DOC. 1840-1868)}

Algo más sencilla, pero sin seguridad plena, resulta la catalogación de piezas posteriores. Después de 1832 no se conoce ningún dibujo de examen, porque ya no debió de haber aprobaciones, al menos obligatorias, para ejercer el arte. Por eso ignoramos cuándo empezó a actuar el platero Ramón Iturralde, que marca obras a las que nos referiremos a continuación, y cuál fue su parentesco, probablemente hijo, con José. En la Enciclopedia se anota a un R. Iturralde como activo de 1840 a $1863^{57}$, lo que se habrá deducido de piezas con marcas cronológicas.

De Ramón Iturralde se conocen obras con marcas cronológicas desde 1842 -en que muere José- a 1864, pero las noticias se prolongan hasta 1868. Una cuchara (colección particular) con marca correspondiente a 1842 lleva una personal que recoge la inicial con punto y el apellido en segunda línea en mayúsculas y en forma ligeramente curva ${ }^{58}$ (Fig. 12). Además de la marca cronológica, una inscripción data el relicario de San Joaquín del convento de carmelitas descalzas de Pamplona en 1844: "A expensas de la cofradía de San Joaquín de Pamplona 1844" (en mayúsculas). La marca personal se ha transcrito con la primera línea "J. R." (no se señala la curvatura de la segunda) y se identifica con un José Ramón Iturralde que no ha apareci-

${ }^{57}$ A. FERNÁNDEZ, R. MUNOA y J. RABASCO, Op.cit., p. 284. A Francisco se le sitúa de 1789 a 1840, lo que es referencia aproximada. cas).

${ }^{58}$ Ibídem, no 974 (se reproduce fotografía de las mar- do nunca en la documentación ${ }^{59}$. Ha de tratarse de una errata, quizá provocada porque resbalara el punzón y dejara una confusa doble impronta. Las crismeras, de arqueta con cubierta troncocónica, conservadas en Izurdiaga, llevan marca de 1846 y la personal con la inicial del nombre ${ }^{60}$; lo mismo sucede con las crismeras de Ripa-Guenduláin ${ }^{61}$. El copón de la iglesia de la Asunción de Miranda de Arga fue arreglado por Ramón Iturralde en $1849^{62}$ y un juego de vinajeras con salvilla de Oyeregui de 1853 lleva la marca personal que venimos comentando ${ }^{63}$. Por fin, el relicario de San Andrés de Narvarte tiene marca de $1864^{64}$ y el pie de una custodia del siglo XVII en Olza, muestra la marca del artífice pero sin cronológica ${ }^{65}$. Después de 1864 tenemos noticia de Ramón Iturralde a través de los anuncios que aparecen en el Anuario General del Comercio. Desde 1865 a 1868, ambos inclusive, que son los años que hemos podido consultar, aparece con nombre y apellidos en tres epígrafes: Joyerías, Plateadores de metales y Platerías. Los anuncios indican la localización en Chapitela 8 y 10, lugar que ocupaba en 1883 la viuda del platero Sasa; la calle conserva su nombre y sigue siendo muy comercial, une la plaza Consistorial y la plaza del Castillo. La referencia en los cuatro años es la siguiente: “Grabador en metales, plateador, dorador y cincelador. Platería y almacén de quincalla y bisutería" 66; acorde con la época, la platería de plata no

${ }^{59}$ M. C. GARCÍA GAINZA (dir.), Catálogo Monumental..., Vol. $\mathrm{V}^{* * *}$, p. 286.

${ }^{60}$ Ibídem, Vol. V*, p. 168.

${ }^{61}$ Ibídem, Vol. V**, p. 378.

${ }^{62}$ Ibídem, Vol. III, p. 227. La pieza fue hecha originariamente por Pedro de Aguinagalde en 1794.

${ }^{63}$ Ibídem, Vol. V*, p. 444.

${ }^{64}$ Ibídem, p. 438.

${ }^{65}$ Ibídem, Vol. V**, p. 431.

${ }^{66}$ Anuario general del Comercio de la Industria y de las Profesiones; de la Magistratura y de la Administración ó Diccionario indicador de todos los habitantes de Madrid de las Provincias y Ultramar, Madrid, 1865, 1866, 1867, 1868. Véanse los epígrafes indicados. 
era su única ocupación, sino que se ampliaba el negocio a géneros antaño rechazados por los plateros. Sólo otro platero de Pamplona se anunciaba en aquellos años en el Anuario General, lo que debemos tomar como prueba de la importancia de su trabajo.

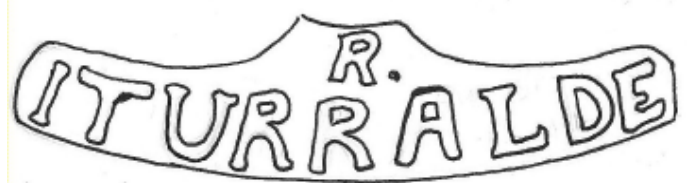

- Fig. 12. Marca de Ramón Iturralde (doc. 18421868). Dibujo de la autora.

Se han publicado algunas obras con una marca que recoge la inicial "F." y el apellido Iturralde (en mayúsculas) completo en una segunda línea. Son las que siguen, contemporáneas de las de Ramón: un cáliz de 1847 y vinajeras con platillo de 1851 en Arizcun $^{67}$ y un copón de 1863 en Falces ${ }^{68}$. Sin haber podido comprobar personalmente la marca de dichas piezas, que se conozcan tan pocas y que no aparezca documento ni anuncio suyo alguno, nos lleva a pensar que se leyó mal la inicial y que, en realidad es una " $R$ " y las obras son de Ramón Iturralde. Además, se mencionó como pieza de un Iturralde sin identificar ${ }^{69}$ un cáliz de 1852 de Luquin $^{70}$ en la que solo se transcribe la sílaba "TUR" que tanto podía corresponder a Ramón Iturralde como a Antonio Iturzaeta, aprobado en 1832.

\section{CONCLUSIÓN}

A través de las piezas que por primera vez publicamos y reproducimos de Francisco Iturralde, además de la documen-

\footnotetext{
${ }^{67}$ M. C. GARCÍA GAINZA (dir.), Catálogo Monumental..., Vol. $\mathrm{V}^{*}$, pp. 310-311.

${ }^{68}$ Ibídem, Vol. III, p. 87. Se data en 1763, pero en esa fecha no se empleaban todavía marcas cronológicas y Francisco tenía sólo dos años.

${ }^{69}$ A. y M. de ORBE SIVATTE, Orfebrería..., p. 18, nota 20 .

${ }^{70}$ M. C. GARCÍA GAINZA (dir.), Catálogo..., Vol. $\mathrm{V}^{* *}$, p. 293; no se identifica la marca.
}

tación inédita -contratos, pagos y anuncios comerciales- que sacamos a la luz sobre este platero y sus probablemente hermano José y sobrino Ramón, acompañado de un análisis más profundo y contrastado de las noticias existentes sobre estos tres plateros, hemos podido aclarar y atribuir correctamente varias piezas, ampliar el conocimiento sobre su producción y establecer y reproducir las marcas de artífice correspondientes a cada uno, incluidas las variantes.

\section{APÉNDICE DOCUMENTAL}

DOCUMENTO 1. Pamplona, 23-11797. Escritura de obligación y fianzas otorgada por el platero Francisco Iturralde para la realización de varias piezas de plata por encargo de la iglesia de Mendavia. (AGN, Protocolos, caja 21.262/1 no 21).

\section{"Pamplona - Mendabia}

En 23 de enero de 1797.

Escritura de obligación y fianzas otorgada por Francisco Yturralde, artífice platero vecino de esta ciudad.

Para la construcción de varias alajas de piezas de plata que ha de hacer dicho Yturralde para la yglesia de la villa de Mendabia.

En la ciudad de Pamplona a veinte y tres de enero de mil setecientos noventa y siete, ante mí el esscribano real y testigos infrascriptos, es presente Francisco Yturralde, artífice platero, vecino de esta ciudad. Y dijo que, por escritura de seis de diciembre del año último de noventa y seis, se convino y ajustó con el patronato eclesiástico y secular de la yglesia parroquial de la villa de Mendabia y administrador de su fábrica, en que dicho Yturralde ha de hacer y construir para la dicha iglesia según arte, una lámpara de plata de peso de quatrocientas onzas, seis can- 
deleros e mesa de altar y su cruz igual y correspondiente de trescientas y setenta onzas, otra cruz de procesiones de ciento y veinte onzas, una calderilla con un ysopo para el asperges de ochenta onzas, dos cetros de ciento y veinte onzas, quatro pares de vinageras con sus respectibos platillos de veinte y quatro onzas y una sacra para las palabras de la Consagración de quarenta onzas y dos sacras más de lababo y Evangelio de veinte onzas, que todas las referidas piezas han de componer mil doscientas y cuarenta y dos onzas, debiéndolas travajar y fabricar con el mayor primor a la moda moderna y según arte e idea que presentó en siete planos o diseños a dicho patronato, debiéndole pagar a dicho Yturralde al respecto de diez reales y medio de plata fuertes por cada onza de plata que pesaren dichas alajas o piezas, y a más quatro reales y medio también de plata fuertes por cada onza por razón de hechuras y lo mismo se le ha de pagar de hechuras por cada una de las onzas de bronce sobredoradas que han de llebar, y a más el bronce y oro que pusiere, siendo de la obligación de dicho Yturralde poner a todas las alajas las piezas de bronce de sobrepuestos dorados arregladas a arte y según corresponda, debiéndole dar adelantado el importe de la plata para la alaja o alajas que le dieren orden de principio a construir y fabricar, y conforme baya entregando dicha alaja o alajas, le ha de pagar y ajustar las echuras y quanto pusiere en las que fuere entregando, y si contemplare dicho Yturralde ser conveniente aumentar el peso de dichas piezas, pueda hacerlo en el todo de dichas alajas hasta mil y trescientas o más, pagándole las hechuras a dicho respecto, pero si el peso excediere de dicho número de onzas, no se le ha de pagar por las que así excedieren más que el balor de la plata y nada de hechuras, siendo obligación de dicho Yturralde, otorgante, el dar fianzas para el total cumplimiento de lo referido, legas llanas y avonadas a satisfacción del patronato como parece de dicha escritura, que una copia firmada y autorizada por Manuel de Almazán, esscribano real, queda con esta esscritura para inserirse en las copias que de ella se dieren y a consecuencia de dicha primera obligación, los del patronato por medio del esscribano infraescripto le han dado orden a dicho Yturralde, otorgante, que haga desde luego los seis candeleros de mesa de altar con su cruz también de mesa de altar, los dos cetros y las tres sacras de Consagración, lababo y Evangelio, que componen como seiscientos pesos duros, y que dichas piezas las ejecute para la festividad de san Juan, veinte y quatro de junio primero viniente, y ratificando en un todo dicha primera obligación y escritura de seis de diciembre de mil setecientos noventa y seis, se obliga nuevamente a construir y hacer para el referido día veinte y quatro de junio, entregándolas dos días antes las referidas piezas de los seis candeleros con su cruz, los dos cetros y tres sacras conforme está pactado en dicha primera escritura y en la misma forma cumplirá en hacer las demás piezas que en ella se contienen, conforme le bayan dando la orden; y por cuenta de las que desde luego ha de empezar, a recivido por medio y mano del esscribano infraescripto, seiscientos pesos duros que son seis mil reales fuertes, que es el importe de la plata de dichas primeras piezas; y de su entrega y numeración que se ha hecho a presencia de los testigos infraescriptos, se tiene por contento y entregado y de ella otorga quitamiento y carta de pago en forma, con obligación que hace de no volver a pedir más en tiempo alguno pena de costas y daños; y para seguridad del cumplimiento de lo contenido en esta escritura y la anterior de seis de diciembre último, dio y presentó por sus fiadores a Josefa Gambarte su muger, y Melchor Arístegui, vecino de esta ciudad, quienes siendo presentes y certificados del riesgo y peligro de esta fianza, y la dicha Josefa, precedente la licencia marital que de derecho se requiere, dispenssa, entran y se constituyen por tales fiadores, llanos pagadores y cumplidores del espresado Francisco Yturralde y obligan, la muger con su dote de arras y conquistas y ambos con todos los demás sus vienes muebles y raíces, derechos $\mathrm{y}$ acciones habidos y por haber, juntos y de mancomún en voz de uno, y cada uno por 
sí simul edin (sic) solidum, renunciando como renuncian la autentica ochita (sic) de diobus (sic) res devendis (sic) y demás leyes de la mancomunidad, avisados de sus disposiciones por mí, el esscribano de que doi fee, a que el referido Francisco Yturralde, principal, cumplirá en todo y por todo con lo que ba obligado, así en esta escritura como en la anterior que queda citada, sin escusa ni dilación alguna y caso no lo hiciere en todo o en parte, pagarán como tales fiadores al patronato de la villa de Mendabia, las cantidades que dicho Yturralde hubiere recivido, con todos los daños, perjuicios y menoscavos que del no cumplimiento resultaren; para lo qual, renuncian también de su fabor la auténtica presente de fide jusoribus (sic) y epistola del dibo Adriano, de que también han sido adbertidos por mí, el esscribano, y a más, la referida Josefa Gambarte, como casada, renuncia las leyes del senatus consulto veleyano, autentica sigua mulier si veame (sic) lei julia de fundo doctalis (sic), $\mathrm{y}$ el derecho de hipotecas, siendo igualmente adbertida de sus disposiciones, de que así bien doi fee, yo el esscribano; y también la doi de que ha jurado en mi mano la observancia y entero cumplimiento en esta escritura. Y dicho Yturralde buelbe a obligarse a la indemnidad de esta fianza, $\mathrm{Y}$ todos, para ser compelidos a quanto ban obligados, prorrogan jurisdicción cumplida a los jueces y justicias de S.M. que de esta causa puedan y deban conocer en forma de redujicata (sic) a cuya jurisdición se someten y renuncian su propio fuero, juez, jurisdicción y domicilio y la ley sit comvenerit de jurisdicione omnium judicum; y así lo otorgaron, siendo presentes por testigos Manuel Pinillos y Juan José Uribarrena, vecino y residente en esta ciudad, y firmaron todos y en fee de ello, firmé yo, el esscribano.

Previniendo antes de firmar, que los seis diseños quedan firmados por dicho Yturralde y el esscribano infraescripto, y el séptimo es conforme al de la lámpara que está haciendo el mismo Yturralde para la capilla de nuestra Señora del Camino: e yo, el dicho esscribano, en virtud de orden que tengo del patronato de Mendabia, acepté a su favor todo lo referido y firmaron ut supra.

Francisco Yturralde, Josefa Gambarte

Melchor de Arístegui

Manuel Pinillos

Juan José Vrivarrena

Ante my, Joseph Carlos Tavar". 